University of Minnesota Morris Digital Well

University of Minnesota Morris Digital Well

6-2021

\title{
Pandemic Pivot: Designing a Participatory Simulation to Support Social Distancing and Remote Learning
}

\author{
K. K. Lamberty \\ University of Minnesota - Morris, lamberty@morris.umn.edu \\ Paul Friederichsen \\ University of Minnesota - Morris, fried701@morris.umn.edu \\ Audrey Le Meur \\ University of Minnesota - Morris, lemeu001@umn.edu \\ Joseph Moonan Walbran \\ University of Minnesota - Morris, walbr037@morris.umn.edu
}

Follow this and additional works at: https://digitalcommons.morris.umn.edu/cs_facpubs

Part of the Educational Technology Commons, Graphics and Human Computer Interfaces Commons, Online and Distance Education Commons, and the Science and Mathematics Education Commons

\section{Recommended Citation}

K.K. Lamberty, Audrey Le Meur, Paul Friederichsen, and Joseph Moonan Walbran. 2021. Pandemic Pivot: Designing a Participatory Simulation to Support Social Distancing and Remote Learning. In Interaction Design and Children (IDC '21). Association for Computing Machinery, New York, NY, USA, 577-582.

DOI:https://doi.org/10.1145/3459990.3465192

This Conference Proceeding is brought to you for free and open access by the Faculty and Staff Scholarship at University of Minnesota Morris Digital Well. It has been accepted for inclusion in Computer Science Publications by an authorized administrator of University of Minnesota Morris Digital Well. For more information, please contact skulann@morris.umn.edu. 


\title{
Pandemic Pivot: Designing a Participatory Simulation to Support Social Distancing and Remote Learning
}

\author{
K.K. Lamberty \\ lamberty@morris.umn.edu \\ University of Minnesota Morris \\ Morris, MN, USA \\ Paul Friederichsen \\ fried701@morris.umn.edu \\ University of Minnesota Morris \\ Morris, MN, USA
}

\author{
Audrey Le Meur \\ lemeu001@umn.edu \\ University of Minnesota Morris \\ Morris, MN, USA \\ Joseph Moonan Walbran \\ walbr037@morris.umn.edu \\ University of Minnesota Morris \\ Morris, MN, USA
}
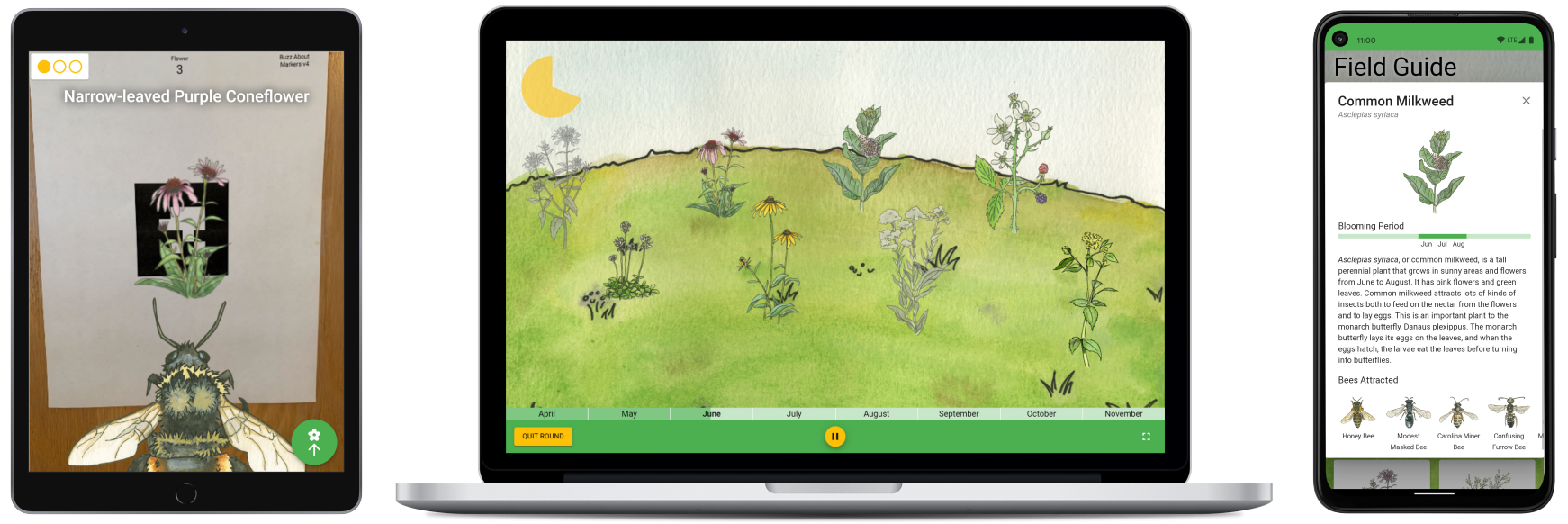

Figure 1: Three screenshots of Buzz About. Left: The individual bee view. Middle: The shared field view. Right: The field guide.

\begin{abstract}
Participatory simulations usually aim to bring simulations off screen into a shared physical space with people acting as agents in the simulation. In this paper, we describe considerations and design decisions related to creating a participatory simulation for use in learning settings with restrictions imposed due to the COVID-19 pandemic where typical classroom interactions were no longer allowed. We describe how our design decisions might help children both "dive in" and "step out" to understand more about pollinators and the prairie in spite of various restrictions on how exactly they can interact with each other. Our simulation, Buzz About, uses augmented reality in a multi-device setting to allow learners to explore the impacts of a prairie restoration on local beneficial pollinators from the perspective of a bee. We focus on supporting scenarios where the children may be in a shared space with social-distancing requirements or participating remotely, but synchronously.
\end{abstract}

Permission to make digital or hard copies of part or all of this work for personal or classroom use is granted without fee provided that copies are not made or distributed for profit or commercial advantage and that copies bear this notice and the full citation on the first page. Copyrights for third-party components of this work must be honored.

For all other uses, contact the owner/author(s).

IDC '21, fune 24-30, 2021, Athens, Greece

(C) 2021 Copyright held by the owner/author(s)

ACM ISBN 978-1-4503-8452-0/21/06.

https://doi.org/10.1145/3459990.3465192

\section{CCS CONCEPTS}

- Human-centered computing $\rightarrow$ Interactive systems and tools; Interaction design process and methods.

\section{KEYWORDS}

Children, Learning, Participatory Simulations, Distance Learning, Augmented Reality

\section{ACM Reference Format:}

K.K. Lamberty, Audrey Le Meur, Paul Friederichsen, and Joseph Moonan Walbran. 2021. Pandemic Pivot: Designing a Participatory Simulation to Support Social Distancing and Remote Learning. In Interaction Design and Children (IDC '21), June 24-30, 2021, Athens, Greece. ACM, New York, NY, USA, 6 pages. https://doi.org/10.1145/3459990.3465192

\section{INTRODUCTION}

The COVID-19 pandemic resulted in many classrooms moving quickly to online or distance learning settings. At that time, we were building a participatory simulation intended for use in a shared physical space without any particular restrictions on physical interactions. Our participatory simulation, Buzz About (see Figure 1), has users role play as bees collecting pollen in different scenarios to inform their recommendations to scientists about what to plant in a prairie restoration project. The original purpose of this research 
was to learn how to design activities and a participatory simulation to support people who are learning about complex systems-in this case, how bees interact with the world, what they do, and what they need. To support learners in their new learning settings-in physical classrooms with social distancing requirements or remote learning-we set out to rethink the design of our system to enable its flexible use in a variety of settings. Our work adds to existing knowledge by setting up the potential to compare a collaborative participatory simulation in a standard setting, in a setting with limited interactions between users in a shared physical space, and in a distributed setting.

In this paper, we begin by describing some relevant aspects of existing research looking at how people learn by taking part in participatory simulations. Next, we describe our participatory simulation, Buzz About, and its intended use. Then, we describe how our participatory simulation might be used in a socially-distanced or remote-learning setting. Finally, we conclude and describe plans for future work with Buzz About.

\section{PARTICIPATORY SIMULATIONS}

Previous work on participatory simulations influences our work in several important ways. Colella established participatory simulations as scenario-based simulations that use a set of fundamental rules. These simulations allow participant experimentation with different conditions over the course of multiple repetitions of the simulation [2]. In this section, we highlight aspects of previous research on participatory simulations that are particularly important when considering design decisions for using our participatory simulation in novel learning environments.

\subsection{Balancing immersion and awareness}

An emphasis in participatory simulations is bringing the simulation off the screen and into the physical environment to immerse learners in the simulation from a first-person perspective [2]. The design of any devices or interfaces used in the simulation should not interfere with social interactions between participants, but it is helpful to have information that can be used by the participants to analyze and reflect on the simulations $[2,5]$.

Understanding complex systems poses many challenges for learners, not least of which is noticing and connecting relationships between different levels or perspectives while simultaneously understanding each level [4]. Further research suggests that simulations with a third-person perspective, or with a combination of first-person and third-person perspectives, help students understand complex systems more than purely first-person simulations [9]. In a shared physical space, awareness about what other participants are doing may be heightened just by interactions and conversations that occur throughout the simulation. In adapting our simulation to socially-distanced classrooms or remote learning scenarios, we must ensure that we do not lose that third-person perspective. Additionally, one concern about immersion in the firstperson perspective-losing sight of the systems-level view [6]-is potentially exacerbated by our use of augmented reality [3]; in socially-distanced or remote learning settings, we especially need to consider how to help learners remain aware of the whole system given that they may be missing cues that would be easier to experience naturally in a standard learning setting in a shared space. It is important to us that, under these new physical limitations, students can still observe other agents and the system as a whole so that they may connect those perspectives to their own experiences as a bee. Therefore, we must create and highlight opportunities for noticing what is going on with other agents and with the overall system.

\subsection{The importance of role playing and movement}

Previous work has studied the impact of role playing and providing opportunities for both "diving in" to be an agent in the simulation and "stepping out" to understand the interactions between agents in the simulation or the overall outcomes of the simulation [1]. The alignment between children's play activities and many of the types of activities involved in a participatory simulation can be leveraged in natural ways to make the first-person perspective more accessible [8]. Utilizing human movement to control agents in the simulation has the potential to alleviate some of the cognitive load associated with understanding the first-person perspective, but can also shift the focus to the first-person too much-obscuring the third-person [6]. When considering how to incorporate movement into games, Lyons et al. recommend tuning physical effort in-game to the reallife cost of the action [7]. We use these ideas together to steer our design decisions to help students participating in different learning scenarios benefit from role playing, even with less potential for movement or fewer social cues to support role play.

\subsection{Participating alone, in parallel, or together}

While the majority of research on participatory simulations for learning considers participants moving about in a shared space, other research explores single-user participatory simulations (SUPS). In their work on SUPS, Langbeheim and Levy briefly compare singleuser participatory simulations and collaborative participatory simulations [6]. They mention that the cognitive load associated with considering the actions of others or focusing on the agent or role may be greater in a collaborative participatory simulation and could overshadow the properties of the overall system. Their work emphasizes the need for support to help learners link the agent-level and macro-level representations so that learners can overcome the impact of splitting their attention. In our work, then, we try to guide students in applying their individual experiences to the higher-level behavior of ecosystems without expecting them to pay attention to many things at once.

Work on collaborative participatory simulations has focused on users working together in a shared space without particular restrictions on movement or interpersonal interactions. We were unable to find any prior work about using participatory simulations synchronously from multiple locations. We also could not find other work about using a collaborative participatory simulation in parallel without direct interaction. However, our work was informed by research about ambient information displays [10]. When making design decisions about our shared display, we kept in mind our goals to raise awareness of actions of other agents without demanding attention or distracting learners. 


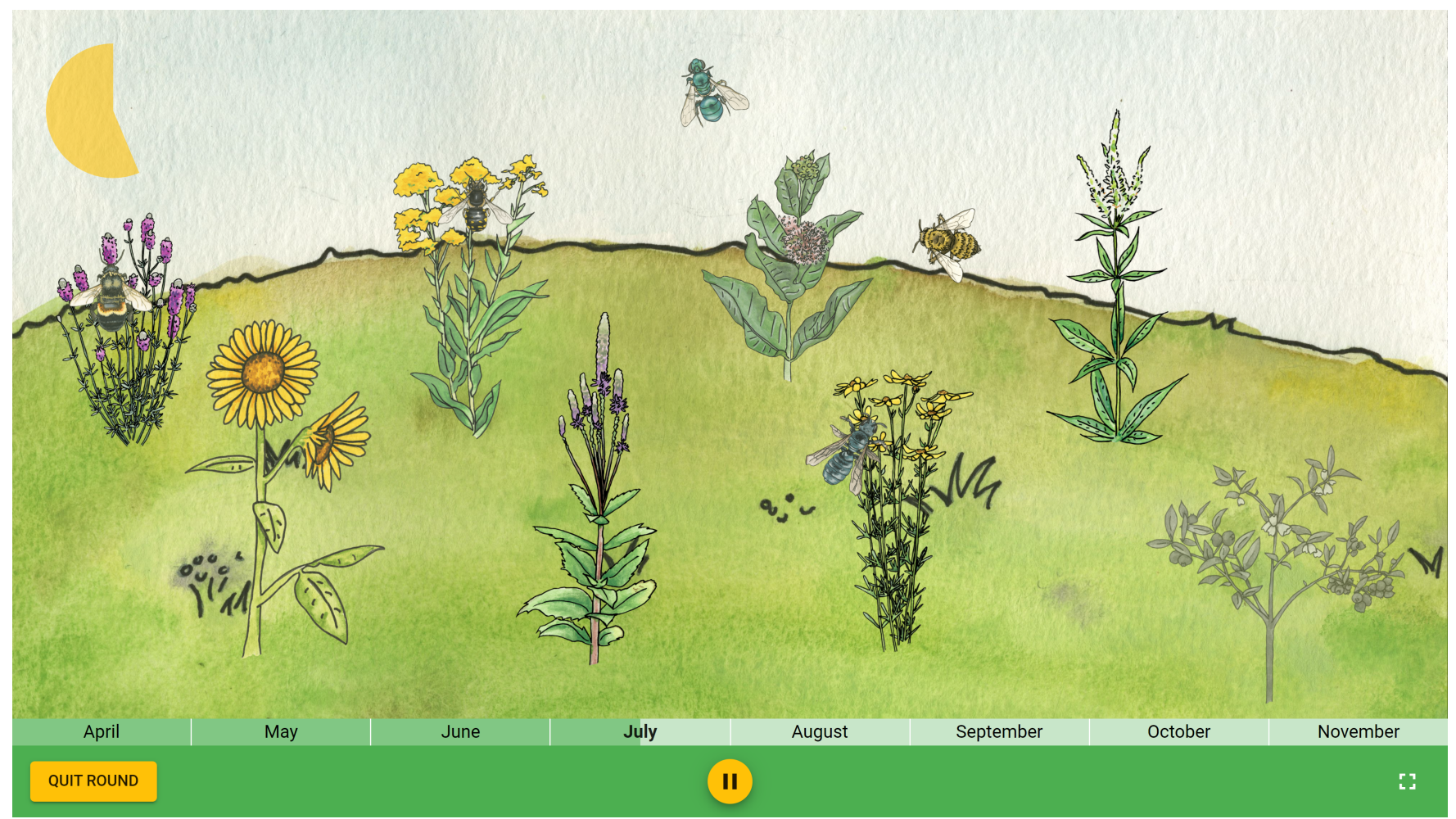

Figure 2: The shared display shows the flowers in the round (in grayscale for those not currently blooming). There are two indicators of time: the timeline along the bottom and the sun timer in the top left. There are bee avatars representing each agent that move between flowers when a bee visits a flower and move off screen when a bee visits its nest.

\section{BUZZ ABOUT}

In our participatory simulation, Buzz About (see Figure 1), people role play as bees collecting pollen in a prairie to learn more about a variety of pollinators: where they live, when they are active, and how different choices for a prairie restoration might impact their ability to collect enough pollen. The activity takes place within a session with opportunities to work through multiple rounds, discussing and reflecting on the activity with support from guides and worksheets that have learners make and justify choices about what plants to include in their recommendations to scientists completing a prairie restoration project. Participation relies on learners having access to two dynamic views: a shared display and an individual display. Learners each control their individual displays and can see the shared display, but only the host can control the shared display. Within the physical environment, there are augmented reality markers to represent prairie flowers and bee nests.

The shared display is either visible in the classroom or online (see Figure 2). We use the shared display as an anchor throughout the activity; it displays information about what is happening throughout a session, both during and between rounds. During rounds, the shared display acts as an ambient information display. According to the taxonomy presented in [10], the shared display conveys a medium amount of information capacity since it tells several important things about the state of the round (e.g., how much time has passed, how much time is left, what time of year it is in the simulation, what flowers are present in the round, what flowers are currently blooming). In addition to information about the round, the shared display shows information about other agents in the simulation, including which bees are active, which flowers they are visiting, and when they are heading to their nests. The notification level of the shared display is also somewhere in the middle since it is meant to make other participants aware of what is happening, but does not interrupt them. Its representational fidelity is somewhat high since each flower corresponds to a specific flower marker and each bee corresponds to a specific agent-another learner taking part in the simulation. The level of aesthetic emphasis in Buzz About is relatively high. The intent of using painted images is to soften the appearance of the bees so they are more approachable for the learners and the overall aesthetic appeal of the application is a priority so that it will draw learners in. Overall, the shared display most resembles a "multiple information consolidator" with slightly less information capacity and more aesthetic emphasis [10].

In a round, each participant uses a mobile device to move their assigned bee in the environment from their nest to various flowers to collect pollen (see Figure 3) and to view the field guide (see Figure 4). What a participant sees when they look at an augmented reality marker through their device depends on how much pollen they are carrying already (see Figure 3(a)), what kind of nest their bee lives in (see Figure 3(b)), and whether or not their bee is compatible with the flower (see Figure 3(c)). 


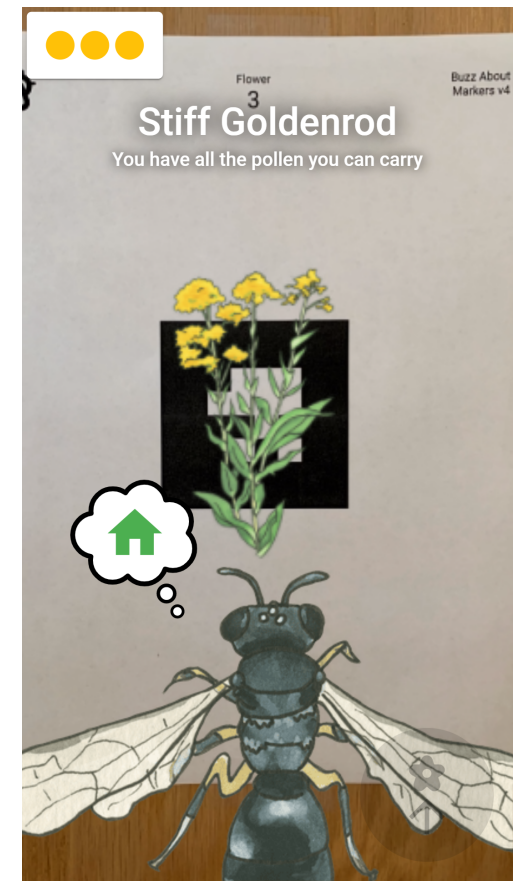

(a) Attempting to visit a flower

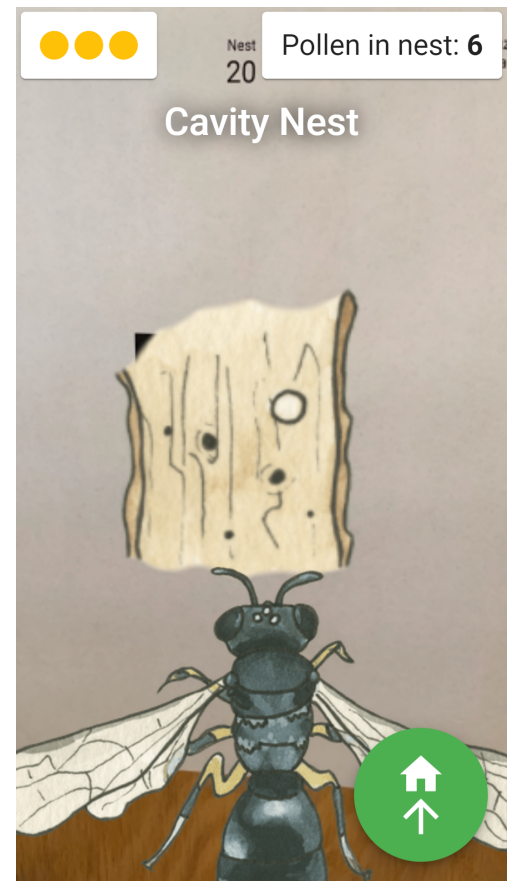

(b) Ready to visit the nest to store pollen

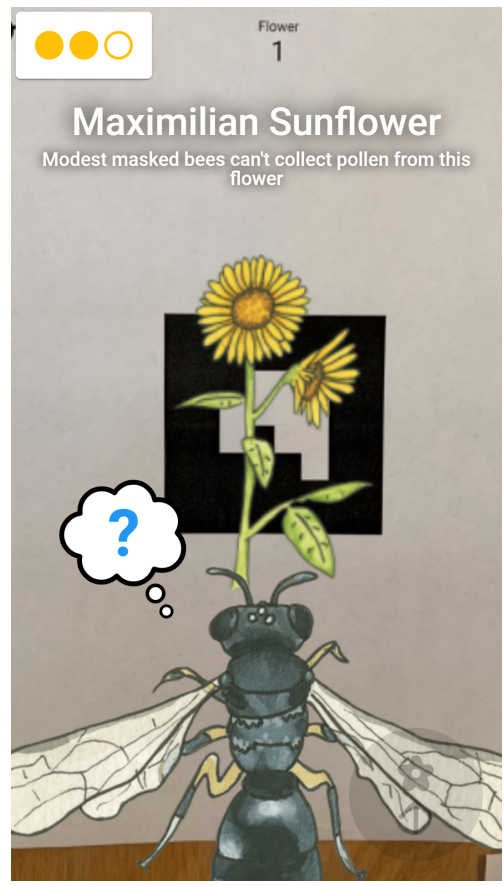

(c) Attempting to visit an incompatible flower

Figure 3: Three examples of interactions through the augmented reality, first-person view.

Since our activity is presented as an opportunity to explore several options for how to approach a prairie restoration project and how to give suggestions about what to plant in a prairie restoration, we provide learners with information about bees and flowers that are native to our area to support their choices for making these recommendations (see Figure 4). We hypothesize that learners will initially make decisions that might be somewhat random with little justification, and then begin to justify their decisions in more meaningful ways once they notice how bees are active at different times, flowers bloom at different times, and not all bees can collect pollen from all flowers. We plan for students to work in pairs or small groups to make their recommendations and to use the field guide to help them make those decisions.

\section{DESIGNING FOR SOCIAL DISTANCING AND REMOTE LEARNING}

To allow students to experience the simulation during the pandemic, we thought of a few ways to change the experience to allow for participating in a classroom with much less movement throughout the shared space or participating synchronously online. We considered how "diving in" to experience the simulation activity from a first-person perspective and "stepping out" to understand the simulation from a third-person perspective might be supported in two different settings: in person with social distancing and synchronous remote learning. We began with the hypothesis that it will be more challenging for participants to see the "big picture" aspects of the simulation in a distance-learning setting, but that the first-person aspects and experiences will be similar in these two settings.

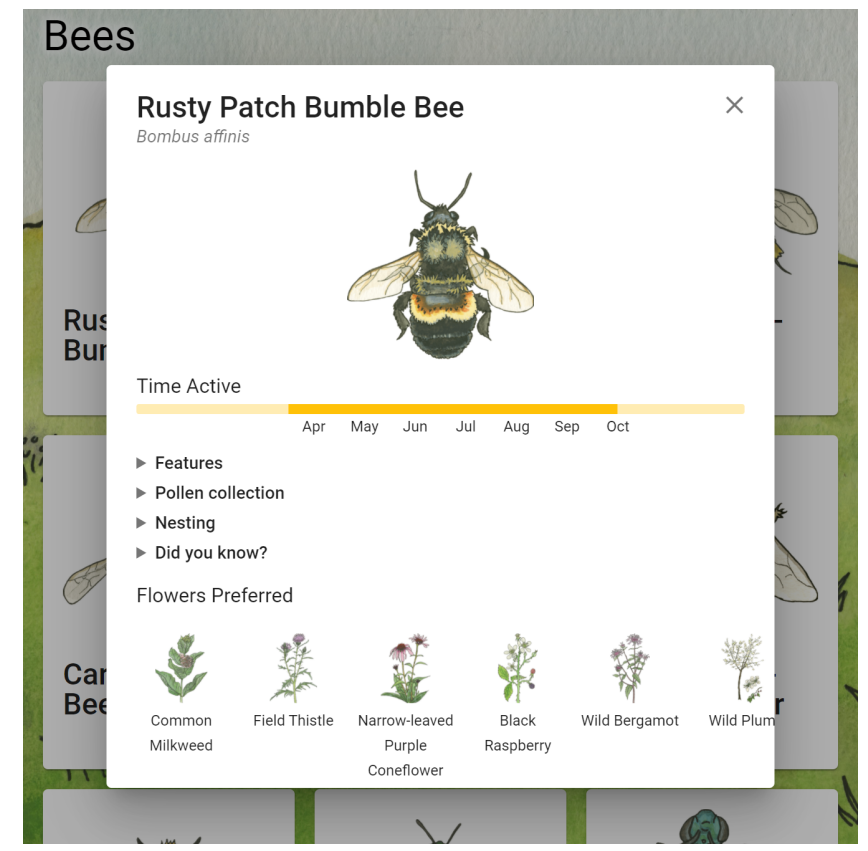

Figure 4: The field guide with the details of the Rusty Patch Bumble Bee opened. It has an illustration of the bee, a timeline showing when it is active, drop-down text sections detailing various information about the species, and a horizontal scrolling list of preferred flowers for the species. 


\subsection{Considerations for a social-distancing scenario}

We identified three main considerations for the social distancing scenario: limitations on the use of space, the impact of reduced movement, and the importance of awareness of and interaction with other students.

4.1.1 Space. Given social distancing guidelines, participation in an in-person classroom would be physically limited to a student's individual desk. The original design included a set of 16 "flower" markers spread throughout the entire classroom, which would not reasonably fit within a student's personal space. To allow students to participate in the simulation while remaining in place, we reduced the number of "flower" markers to 8 markers plus a "nest" marker, with each student receiving their own copy of the identical set.

4.1.2 Movement. We hypothesized that reduced movement would impact students' experiences with the simulation in several ways. First, students would underestimate the effort required for bees to find and gather pollen from suitable flowers. For example, in the original scenario, a student might find it significantly more difficult to collect pollen and return it to their nest when their bee is only compatible with a couple flowers. The student would be forced to walk back and forth for each pollen unit. In contrast, in the socially-distanced scenario of students at their desks with all the markers in front of them, the student would only be mildly inconvenienced, since they would only have to move their arms a little bit to scan more markers. This unawareness of bees' effort may reduce the epistemic impact of the simulation [7].

Additionally, we realized that the lack of movement within the socially-distanced environment would require changes to the timing of the simulation. One feature of our simulation is a timer that mimics time passing through the seasons. In the original simulation, a student took time to move to each marker so each round of the simulation was timed accordingly. In contrast, students seated at their desks would likely take less time between scanning markers. This difference in timing may impact expectations programmed into the simulation, such as how much pollen we would expect a bee to collect in order to have a "successful" season.

4.1.3 Awareness. When students are visiting flowers in the socialdistancing scenario, their activity is less noticeable to others. In that case, students are likely to be less aware of the experiences of other bees in the simulation-they won't know if another participant's bee is inactive or busily gathering pollen because the act of scanning a marker is much less noticeable. Since students in this scenario are confined to their own space, they may focus more on their individual experiences than they would have in an unrestricted environment. Conversely, a student who moves around the space may be more likely to share their experiences with others, or see the actions others are taking. For instance, while students in the socially-distanced scenario have the same set of "flower" markers, we suspected that students would be less likely to notice when the experiences of others with a particular flower differ from their own.

Furthermore, even if students notice interactions of some other bees, they are likely to have limited exposure to a variety of experiences. A student seated at an individual desk probably only interacts with the students seated immediately adjacent. Meanwhile, a student who moves around the space has the opportunity to interact with more, if not all other, students. Thus, we infer that the students in the original classroom scenario would be exposed to a larger diversity in experience than the students in the socially-distanced scenario.

\subsection{Considerations for a remote-learning scenario}

Considerations for remote-learning scenarios vary somewhat from those that are important for learners in a shared space. First, we looked at how to set up the environment for students. Then, we considered how to help learners situate themselves in the activity in spite of the absence or diminished saliency of cues from not having a large shared display (e.g., a projected display) and from not being in the same space as other participants. Finally, we proposed extra supports for discussion between rounds to help learners connect first-person and third-person perspectives.

4.2.1 Setting up a remote-learning scenario. Using a multi-user participatory simulation in a remote-learning setting presents a significant challenge in terms of implementation. First, we determined that, due to the multi-user nature of our simulation, participation could not be asynchronous. We want students to observe how a given ecosystem supports multiple bee species; for students to see that, they would need to all participate at the same time. The solution we settled on required students to have two devices: one larger device (e.g., a laptop or desktop computer) on which the student would connect to the class via video conferencing, and a smaller mobile device on which they would participate in the simulation. The teacher would screen-share the large display and facilitate discussion through the video conference. The student would be instructed to place the markers around their own space. Students would place their nest marker by their larger device, so that they would have plenty of opportunities to look at the shared display and notice what's happening in the prairie ecosystem, where in the season the round is, and how much time remains. We would use the 8-flower marker set from the socially-distanced scenario since most home spaces are smaller than classroom spaces.

4.2.2 Awareness. In a distance-learning scenario, students have no way to naturally notice the actions of others. In a classroom, students may notice when other students are struggling to find flowers to gather pollen from, or they may talk with their friends about their struggles. Remote participants have fewer opportunities for interaction. On the other hand, distancing students from each other may ameliorate Langbeheim and Levy's concerns about cognitive load-the students' attention wouldn't be divided between their own actions and the actions of their classmates [6].

Any design decision that brings the third-person perspective to the remote learners does so at the cost of splitting students' attention between first-person and third-person perspectives, but we know that the third-person perspective is valuable [9]. We modified the large display to make it easier to see the actions of other students. Originally, we intended the large display to communicate what flowers are present in a round, which of them are blooming at the moment, and how much time the students have left. To support 
distance learners, however, we also made the shared display show an indication every time a student visits a flower (See Figure 2). That way, remote participants can get a sense of what flowers other bees visit most frequently-which may differ from the flowers they themselves visit most frequently. Since the shared display provides this additional information, it can help the students "step out" and reason about the system.

4.2.3 Connecting perspectives. In addition to it being difficult for students to notice the third-person perspective, even with some awareness, it may still be difficult for teachers to support learners in linking their individual experiences to the macro-level properties of the system. To help overcome this challenge, we propose to add post-round information to the shared display after each round to explicitly support discussion and reflection about what just happened With the insights from the post-round summary, students could discuss what flowers they found themselves visiting most often and what difficulties they encountered when collecting pollen. For example, there might be long stretches of time when few flowers are blooming. Different bee species visit different flowers; sometimes, an ecosystem will have all the flowers that one species of bee needs, but none of the flowers that a different species needs. And, even if a student does not bring up their individual experience to share it with others, some information about what happened would still be visible during the discussion and reveal at least some useful information. Post-round discussion gives students time to reflect on experiences they had during the round and to notice where their own experiences differed from those of others, connecting first-person experiences to the system as a whole.

\section{CONCLUSION}

In this paper, we present considerations and design decisions in the context of creating a participatory simulation for use in a variety of learning settings. Some key ideas in the participatory simulation research space provide a useful lens for examining Buzz About in settings where learners need to maintain social distancing or where learners are participating remotely. Namely, we describe how we created supports for children to be able to immerse themselves in the simulation as bees (diving in), to see and be aware of the impacts of the prairie restoration on all of the bees (stepping out), and to connect these two perspectives to gain a better understanding of the prairie ecosystem.

\section{FUTURE WORK}

Although we designed a research protocol to collect all of our data remotely, we have not been able to recruit teachers and schools to participate in this research. We heard back from principals that teachers are already juggling so much due to the pandemic that it was not a good time to add anything. In the meantime, we took time to play test for sense checking periodically and hired a teacher consultant to assist in our design process with a focus on understanding how to help teachers adopt this activity for use in their classrooms as easily as possible.

We are hopeful that we will be able to put Buzz About in the hands of teachers and students in the near future and gather data that will help us understand more about how to design participatory simulations for use in a variety of learning settings. Our plan is to have teachers use Buzz About with their classes in whichever learning setting makes the most sense for them. We will collect audio and video data along with log files to code for behaviors that indicate "diving in" or "stepping out" so that we can analyze student interactions and understand more about what it looks like for students to engage with participatory simulations in a variety of learning settings.

\section{ACKNOWLEDGMENTS}

Funding for this project was provided by the Minnesota Environment and Natural Resources Trust Fund as recommended by the Legislative-Citizen Commission on Minnesota Resources (LCCMR). The Trust Fund is a permanent fund constitutionally established by the citizens of Minnesota to assist in the protection, conservation, preservation, and enhancement of the state's air, water, land, fish, wildlife, and other natural resources.

This work relies upon many technical and artistic contributions to the design and development of Buzz About by a team of undergraduates over the course of several years including: Paul Friederichsen, Joe Walbran, Waller Li, Utkarsh Kumar, Nathan Foss, Erik Rauer, Audrey Le Meur, Matthew Munns, Michael Small, Shawn Reuter, Nicolas Robertson, Olivia Carlson, and Elizabeth Stevens. Holly Carrington provided consulting from a teacher perspective to help improve the design. The framed device screenshots in Figure 1 were created using the Android Device art generator and MockUPhone.

\section{REFERENCES}

[1] Edith Ackermann. 1996. Perspective-Taking and object Construction. In Constructionism in Practice: Designing, Thinking, and Learning in a Digital World, Yasmin Kafai and Mitchel Resnick (Eds.). Lawrence Erlbaum Associates, Mahwah, New Jersey, Chapter 2, 25-37.

[2] Vanessa Colella. 2000. Participatory Simulations: Building Collaborative Understanding Through Immersive Dynamic Modeling. Fournal of the Learning Sciences 9, 4 (10 2000), 471-500. https://doi.org/10.1207/S15327809JLS0904_4

[3] Matt Dunleavy, Chris Dede, and Rebecca Mitchell. 2009. Affordances and limitations of immersive participatory augmented reality simulations for teaching and learning. Journal of Science Education and Technology 18, 1 (2 2009), 7-22. https://doi.org/10.1007/s10956-008-9119-1

[4] Cindy E. Hmelo-Silver and Merav Green Pfeffer. 2004. Comparing expert and novice understanding of a complex system from the perspective of structures, behaviors, and functions. Cognitive Science 28, 1 (1 2004), 127-138. https: //doi.org/10.1207/s15516709cog2801_7

[5] Eric Klopfer, Susan Yoon, and Luz Rivas. 2004. Comparative analysis of Palm and wearable computers for participatory simulations. Fournal of Computer Assisted Learning 20, 5 (2004), 347-359. https://doi.org/10.1111/j.1365-2729.2004.00094.x

[6] Elon Langbeheim and Sharona T. Levy. 2019. Diving into the particle model: Examining the affordances of a single user participatory simulation. Computers and Education 139 (10 2019), 65-80. https://doi.org/10.1016/j.compedu.2019.05. 006

[7] Leilah Lyons, Brian Slattery, Priscilla Jimenez, Brenda Lopez, and Tom Moher. 2012. Don't forget about the sweat: Effortful embodied interaction in support of learning. In Proceedings of the 6th International Conference on Tangible, Embedded and Embodied Interaction, TEI 2012. ACM, New York, NY, USA, 77-84. https: //doi.org/10.1145/2148131.2148149

[8] Kylie Peppler, Joshua Danish, Benjamin Zaitlen, Diane Glosson, Alexander Jacobs, and David Phelps. 2010. BeeSim: Leveraging wearable computers in Participatory Simulations with young children. In Proceedings of IDC2010: The 9th International Conference on Interaction Design and Children. ACM Press, New York, New York, USA, 246-249. https://doi.org/10.1145/1810543.1810582

[9] Kylie Peppler, Naomi Thompson, Joshua Danish, Armin Moczek, and Seth Corrigan. 2020. Comparing first- and third-person perspectives in early elementary learning of honeybee systems. Instructional Science 48 (2020), 291-312. https://doi.org/10.1007/s11251-020-09511-8

[10] Zachary Pousman and John Stasko. 2006. A Taxonomy of Ambient Information Systems: Four Patterns of Design. In Proceedings of the Working Conference on Advanced Visual Interfaces (Venezia, Italy) (AVI '06). Association for Computing Machinery, New York, NY, USA, 67-74. https://doi.org/10.1145/1133265.1133277 